\title{
Current Strategies and Recent Advances in Gynaecological Oncology Imaging
}

\author{
EMF Wong ${ }^{1}$, AYT Lai ${ }^{1}$, EYP Lee ${ }^{2}$ \\ ${ }^{I}$ Department of Radiology, Pamela Youde Nethersole Eastern Hospital, Hong Kong \\ ${ }^{2}$ Department of Diagnostic Radiology, The University of Hong Kong, Hong Kong
}

\begin{abstract}
Imaging is now a crucial tool in the management of gynaecological cancers to optimise clinical outcomes. This review provides an update on the current role and future trends of imaging in cervical, endometrial, and ovarian cancers. Modern imaging protocols, post-processing techniques, functional imaging modalities and reporting systems are discussed in the setting of staging and guiding of treatment decisions.
\end{abstract}

Key Words: Endometrial neoplasms; Genital neoplasms, female; Ovarian neoplasms; Uterine cervical neoplasm

\section{中文摘要}

\section{婦科腫瘤影像學的當前策略和最新谁展}

\author{
黃文鳳、黎爾德、李燕蘋
}

\begin{abstract}
影像學是現時婦科腫瘤治療優化臨床轉歸的關鍵工具。本文描述當前子宮頸癌、子宮內膜癌和卵巢 癌影像學的角色和未來趨勢。從腫瘤分期及指導治療決策的角度討論現代影像學的掃描方案、後處 理技術、功能性影像學方法和報告系統。
\end{abstract}

\footnotetext{
Correspondence: Dr EMF Wong, Department of Radiology, Pamela Youde Nethersole Eastern Hospital, Hong Kong

Email:esthermfwong@gmail.com
}

Submitted: 27 Jan 2019; Accepted: 13 Mar 2019

Contributors: All authors designed the study, acquired the data, analysed the data, drafted the manuscript, and critically revised the manuscript for important intellectual content. All authors had full access to the data, contributed to the study, approved the final version for publication, and take responsibility for its accuracy and integrity.

Conflicts of Interest: All authors have disclosed no conflicts of interest.

Funding/Support: This research received no specific grant from any funding agency in the public, commercial, or not-for-profit sectors.

Ethics Approval: Patients were treated in accordance with the Declaration of Helsinki. All patients provided informed consent for all treatments and procedures.

Acknowledgement: We would like to thank Dr Amy TY Chang and Dr Rebecca MW Yeung from the Department of Clinical Oncology, Pamela Youde Nethersole Eastern hospital for contributing to the figures of magnetic resonance imaging-guided brachytherapy. 


\section{INTRODUCTION}

Imaging in gynaecological oncology has been revolutionised due to the advances in magnetic resonance imaging (MRI) and functional imaging in the past decades. Imaging methodologies have been integrated into disease diagnosis, staging, and treatment. The aim of this review is to provide an update on the current role and future trends of imaging in cervical, endometrial and ovarian cancers. Modern imaging protocols, postprocessing techniques, functional imaging modalities and reporting systems are discussed in the setting of staging and guiding of treatment decisions.

\section{CERVICAL CANCER}

Cervical cancer is the seventh most common cancer in Hong Kong with about 500 new diagnoses every year. As there is no territory-wide screening programme in Hong Kong and the free human papillomavirus vaccination programme started only in 2019 , the prevalence of cervical cancer is not expected to fall until a decade later. More than half of the patients present with disease stage II or above. ${ }^{1}$ Precise staging at diagnosis is essential in order to optimise treatment. Early cervical cancer (International Federation of Gynecology and Obstetrics [FIGO] stage IIA or below) can be treated with radical hysterectomy with or without pelvic lymphadenectomy. For selected cases of early cancer, fertility-sparing surgery can be offered to patients who have not yet completed their families. ${ }^{2,3}$ Locally advanced disease is treated by chemoradiotherapy. ${ }^{4,5}$

The 2018 FIGO revised staging incorporated imaging findings into the staging system for the first time. Prior to the revision, FIGO staging for cervical cancer was entirely based on clinical and surgical findings. The revised system stated that imaging and pathology findings can be used to supplement tumour size and extent at all stages. In addition, there was a newly introduced "stage IIIC" for lymph node involvement, which is further subdivided to IIIC1 (pelvic lymph node) and IIIC2 (para-aortic lymph node). A small letter " $\mathrm{r}$ " for imaging and a "p" for pathology is used as a suffix to the stage to denote the method of lymph node detection. ${ }^{6}$

MRI is the imaging modality of choice in evaluating local disease extent given its exquisite soft tissue resolution. ${ }^{6}$ The presence of parametrial invasion, which upstages disease to at least FIGO IIB and classifies the disease as locally advanced, is best identified by MRI, with sensitivity and specificity of $73 \%$ and $93 \%$, respectively. ${ }^{7}$ T1-weighted images (T1WI) can be useful to visualise haematometra, lymphadenopathy, and bone metastases, and should be incorporated in the MRI protocol (Table 1). ${ }^{8}$

To optimise the assessment of the parametrium, oblique axial images perpendicular to the long axis of the cervix are essential (Figure 1). ${ }^{8}$ An intact hypointense fibrous stromal ring on T2-weighted images (T2WI) has high negative predictive value for parametrial invasion. Signs of parametrial invasion include $\mathrm{T} 2$ intermediate signal in the parametrium with spiculated borders and encasement of periuterine vessels (Figure 2). ${ }^{9,10}$ Local invasion is well depicted on MRI. Abnormality of the urinary bladder on MRI is not uncommon..$^{11}$ Bullous oedema of the urinary bladder, which is seen on T2WI as markedly hyperintense thickening of the urinary mucosa, cannot be distinguished from mucosal involvement (Figure 3). ${ }^{12}$ Cystoscopy and biopsy are needed to confirm mucosal involvement.

Endovaginal ultrasound is an inexpensive method for visualisation of the vaginal wall and outer contour of the cervix. ${ }^{13,14}$ Intravenous contrast gives no significant improvement in diagnostic accuracy. ${ }^{15}$

The presence of metastatic pelvic lymphadenopathy is an important adverse prognostic indicator ${ }^{16}$ and has been revised in the latest FIGO 2018 staging system. ${ }^{6}$ Compared to the 2014 staging system, the presence of pelvic and paraaortic lymphadenopathy now upgrades the disease to stage IIIC1 and IIIC2, respectively. Conventionally, size and shape criteria were used to differentiate metastatic from benign nodes. Morphology indicators such as lobulated or spiculated borders are highly specific but not sensitive. Size criteria vary in accuracy, sensitivity and specificity depending on the cut-off thresholds. ${ }^{17}$ Diffusion-weighted imaging (DWI) in conjunction with T2WI increases the ability of MRI to differentiate benign from malignant nodes (Figure 4). A meta-analysis by Shen et $\mathrm{al}^{18}$ involving 15 studies found a pooled sensitivity and specificity of $85 \%$ and $84 \%$ for DWI. The analysed studies were, however, heterogeneous due to a lack of optimal standardised DWI protocol among studies. Metabolic imaging based on 18-fluorodeoxyglucose positron emission tomography/computed tomography (FDG-PET/CT) adds to the diagnostic accuracy of nodal involvement. Meta-analysis showed that FDG-PET/CT had a pooled sensitivity and specificity of $82 \%$ and $95 \%$ in determining pelvic lymph node involvement, compared to $56 \%$ and $91 \%$ respectively by MRI. ${ }^{19}$ With 
Update on Gynaecological Oncology Imaging

Table 1. Sample scanning protocol for common gynaecological malignancy.*

\begin{tabular}{|c|c|c|c|}
\hline Sequence & Plane & Technical aspects & Comments \\
\hline \multicolumn{4}{|l|}{ Cervical cancer } \\
\hline T1 & Axial & $\begin{array}{l}\text { Include whole pelvis, large FOV } \\
(\text { e.g., } 330 \times 330) \text {, ST } 5 \mathrm{~mm}\end{array}$ & $\begin{array}{l}\text { Assessment of pelvic side wall, lymph } \\
\text { node and metastasis }\end{array}$ \\
\hline T2 FS & Axial & $\begin{array}{l}\text { Include whole pelvis, large FOV } \\
(\text { e.g., } 330 \times 330) \text {, ST } 5 \mathrm{~mm}\end{array}$ & $\begin{array}{l}\text { Assessment of pelvic side wall, lymph } \\
\text { node and metastasis }\end{array}$ \\
\hline \multirow[t]{2}{*}{ T2 } & Sagittal & Small FOV (e.g., $200 \times 200$ ), ST 3 mm & For assessment of parametrial invasion \\
\hline & $\begin{array}{l}\text { Oblique axial and coronal with } \\
\text { respect to long axis of cervix }\end{array}$ & & \\
\hline DWI & Sagittal & $\begin{array}{l}\text { With at least two b-values, from 0-2000 } \\
\text { (e.g., b }=50,500,1000) \text {, ST } 5 \mathrm{~mm}\end{array}$ & \\
\hline \multicolumn{4}{|l|}{ Endometrial cancer } \\
\hline T1 & Axial & $\begin{array}{l}\text { Include whole pelvis, large FOV } \\
(\text { e.g., } 330 \times 330) \text {, ST } 5 \mathrm{~mm}\end{array}$ & $\begin{array}{l}\text { Assessment of pelvic side wall, lymph } \\
\text { node and metastasis }\end{array}$ \\
\hline T2 FS & Axial & $\begin{array}{l}\text { Include whole pelvis, large FOV } \\
(\text { e.g., } 330 \times 330) \text {, ST } 5 \mathrm{~mm}\end{array}$ & $\begin{array}{l}\text { Assessment of pelvic side wall, lymph } \\
\text { node and metastasis }\end{array}$ \\
\hline $\mathrm{T} 2$ & $\begin{array}{l}\text { Sagittal } \\
\text { Oblique axial and coronal with } \\
\text { reference to long axis of uterus }\end{array}$ & Small FOV (e.g., $200 \times 200$ ), ST 3 mm & $\begin{array}{l}\text { Oblique axial and coronal images for } \\
\text { assessment of depth of myometrial } \\
\text { invasion }\end{array}$ \\
\hline DWI & Sagittal & $\begin{array}{l}\text { With at least two b-values, from 0-2000 } \\
\text { (e.g., 50, 500, 1000), ST } 5 \mathrm{~mm}\end{array}$ & \\
\hline 3D T1 post-contrast FS & Axial & $\begin{array}{l}50 \mathrm{~s}, 2.5 \mathrm{~min} \text { and } 5 \mathrm{~min} \\
1 \mathrm{~mm} \times 1 \mathrm{~mm} \text { in-plane resolution }\end{array}$ & \\
\hline \multicolumn{4}{|l|}{$\begin{array}{l}\text { Ovarian mass } \\
\text { characterisation }\end{array}$} \\
\hline T1 in/out phases & Axial & $\begin{array}{l}\text { Include whole pelvis, large FOV } \\
(\text { e.g., } 330 \times 330) \text {, ST } 5 \mathrm{~mm}\end{array}$ & Assessment of fat content \\
\hline T2 FS & Axial & $\begin{array}{l}\text { Include whole pelvis, large FOV } \\
(\text { e.g., } 330 \times 330) \text {, ST } 5 \mathrm{~mm}\end{array}$ & $\begin{array}{l}\text { Assessment of pelvic side wall, lymph } \\
\text { node and metastasis }\end{array}$ \\
\hline T2 & $\begin{array}{l}\text { Axial plus choice of sagittal or } \\
\text { coronal }\end{array}$ & Small FOV (e.g., $200 \times 200$ ), ST 3 mm & \\
\hline DWI & Axial & $\begin{array}{l}\text { With at least two b-values, from 0-2000 } \\
\text { (e.g., 50, 500, 1000), ST } 5 \mathrm{~mm}\end{array}$ & \\
\hline T1 post-contrast FS & Axial & $\begin{array}{l}3 \mathrm{D} \text { T1 FS with } 1 \mathrm{~mm} \times 1 \mathrm{~mm} \text { in-plane } \\
\text { resolution }\end{array}$ & \\
\hline
\end{tabular}

Abbreviations: $3 \mathrm{D}$ = three-dimensional; DWI = diffusion-weighted imaging; FOV = field of view; FS = fat-saturated; ST = slice thickness; T1 = T1-weighted; T2 = T2-weighted.

* Preparation: Fasting for at least 4 hours. Antiperistaltic agent immediately before examination (e.g., 1 mg glucagon). Moderately filled bladder.

these, FDG-PET/CT offers higher specificity while DWI-MRI is more sensitive in identifying nodal involvement in cervical cancer. ${ }^{20}$

\section{Fertility Preservation}

Fertility sparing treatment such as conisation and trachelectomy can be alternatives to radical surgery in disease of FIGO 1B1 or below. Selection of cases requires a multidisciplinary approach and MRI plays a key role in this..$^{21,22}$

In addition to parametrial assessment, preoperative MRI gives accurate delineation of the craniocaudal extent of tumour, especially with endocervical cancer and its relationship to the internal os. Measurement on MRI correlates well with pathological measurement.
A distance of $5 \mathrm{~mm}$ to $10 \mathrm{~mm}$ between the tumour and the internal os puts the patient at high risk for local recurrence after surgery. ${ }^{23,24}$ Other factors to consider include a maximum tumour size of $<2 \mathrm{~cm}$ with sufficient cervical length after resection (at least $1 \mathrm{~cm}$ ), absence of deep cervical stromal invasion, and absence of lymph node involvement. ${ }^{25}$

\section{Image-guided Brachytherapy}

The GEC-ESTRO (The Groupe Européen de Curiethérapie and the European SocieTy for Radiotherapy \& Oncology) guidelines recommend MRI-guided brachytherapy as a component of the radiotherapy in locally advanced cervical cancer treated with chemoradiotherapy (FIGO IB-IVA). ${ }^{26}$ Studies showed that it improved local control and overall survival 


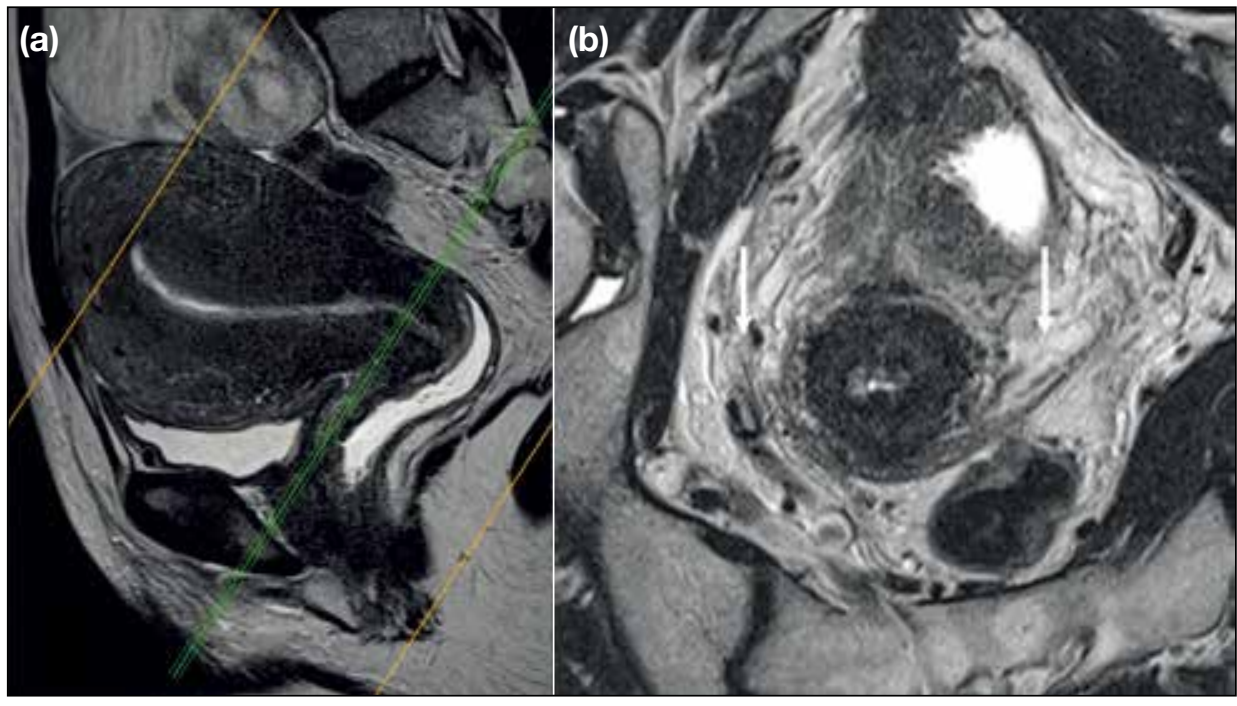

Figure 1. (a) Midline T2-weighted sagittal scan. Green line denotes the plane of oblique axial. (b) T2weighted oblique axial scans. Normal parametrium (arrows).

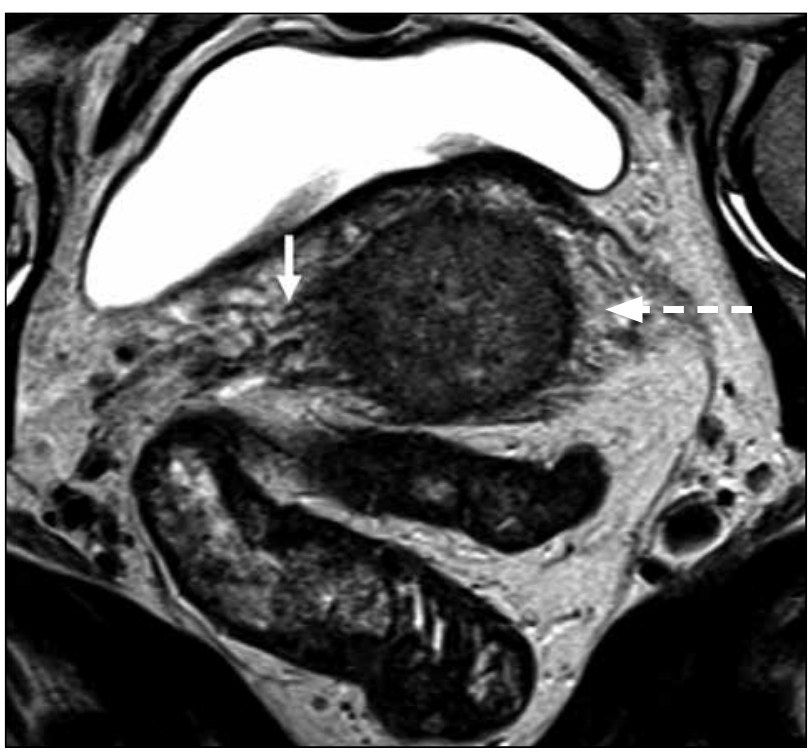

Figure 2. Spiculated soft tissue on the right side suggestive of parametrial invasion (solid arrow). Normal left parametrium with intact stromal line for comparison (dotted arrow).

as compared with two-dimensional radiation planning of previous generation ${ }^{27,28}$ Brachytherapy was historically planned using orthogonal radiographs. From then it evolved to CT-based three-dimensional planning in the 1990's. Compared with traditional CT/X-ray-guided approaches, MRI gives superior contrast delineation and thus makes better tumour delineation from normal tissue. ${ }^{29,30}$ Three-dimensional contouring allows dose escalation to residual disease while sparing the organs at risk, hence improves local control and reduces complication rate (Figure 5).

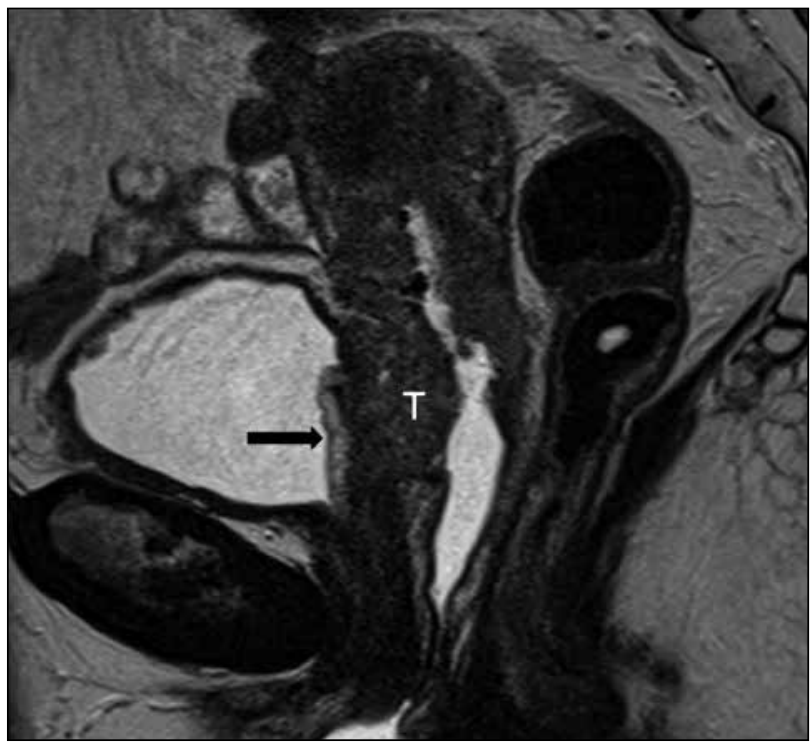

Figure 3. Sagittal T2-weighted magnetic resonance imaging for staging. Cervical tumour (T) centred at the anterior lip. Bullous oedema of the urinary bladder (arrow). This should not be taken as mucosal invasion of bladder unless proven by biopsy.

Brachytherapy is performed following whole pelvis irradiation. The regimen of brachytherapy varies. Planning MRI for brachytherapy is performed immediately after applicator insertion. Logistics on how to minimise transfer time between operating theatre and MRI suite, and to the radiation suite have to be worked out, in addition to the appointment booking and coordination among different units. ${ }^{31}$

Scanning time is an important factor to consider with the applicator in situ. Shorter scanning time minimises 


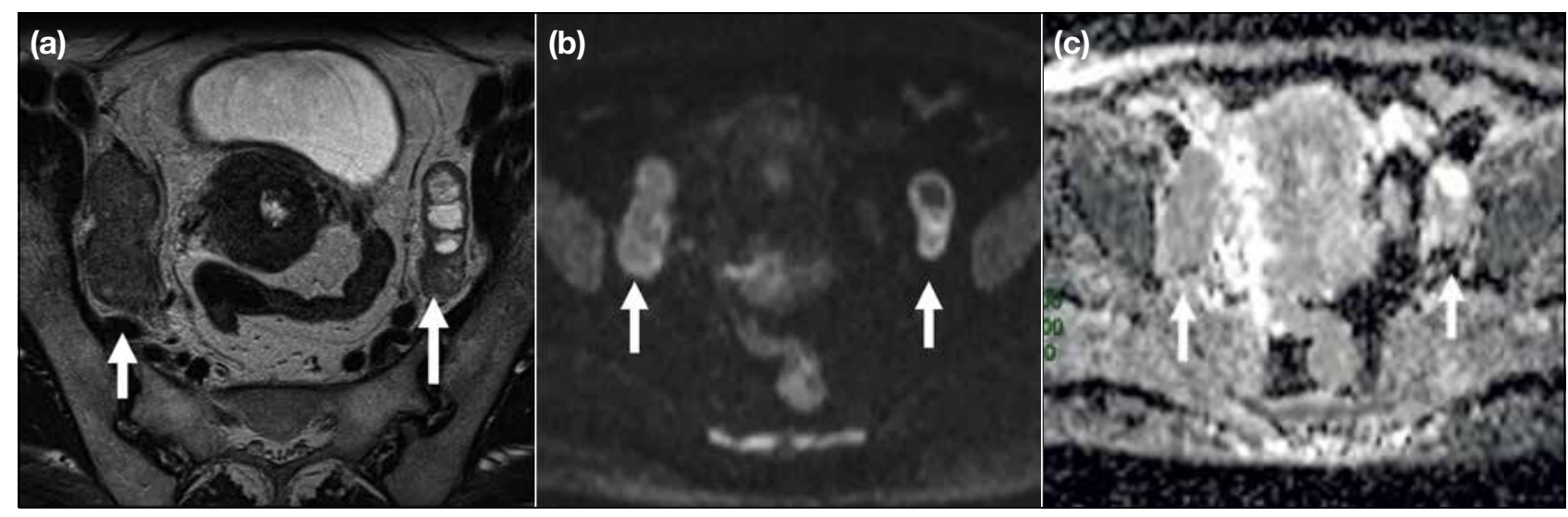

Figure 4. Case of cervical cancer with bilateral lymphadenopathy. (a) T2-weighted images showing bilateral pelvic side wall lymphadenopathy (arrows). (b) A lymph node showing heterogeneous signal (arrows) on the left side. (c) The lymph nodes are hyperintense (arrows) on diffusion-weighted imaging $(\mathrm{b}=1000)$ and hypointense on apparent diffusion coefficient.

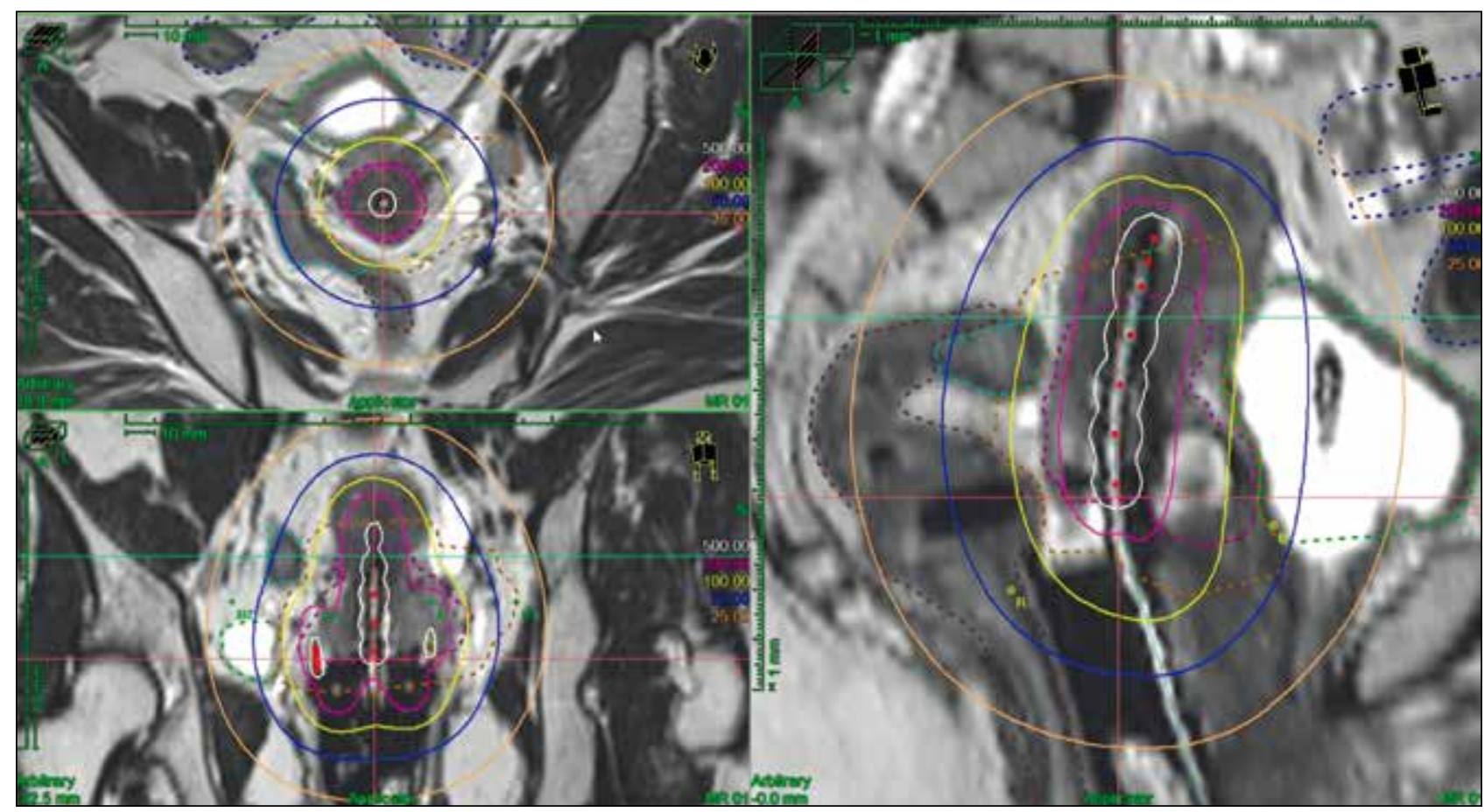

Figure 5. Contour line drawn with magnetic resonance image guidance for radiotherapy planning. (Image courtesy of Dr Amy TY Chang and Dr Rebecca MW Yeung, Department of Clinical Oncology, Pamela Youde Nethersole Eastern Hospital)

patient discomfort and facilitates appointment booking in a busy radiology unit. According to GEC-ESTRO recommendations, mandatory sequences with an applicator are T2WI acquired in axial, coronal and sagittal planes through the cervix (Figure 6) to delineate the urinary bladder, uterus, and rectum. ${ }^{29}$ T2WI orthogonal to the MRI table can be added if required for treatment planning. ${ }^{32}$ DWI and post-contrast sequences are non-essential for this purpose.

\section{ENDOMETRIAL CANCER}

The global incidence of endometrial cancer is on the rise, with a postulated association with increased exogenous hormones use, endogenous hormone exposure, and obesity. ${ }^{33}$

The presence of deep myometrial invasion, defined by tumour invasion beyond half of the myometrial thickness, is positively correlated with pelvic lymphadenopathy and 


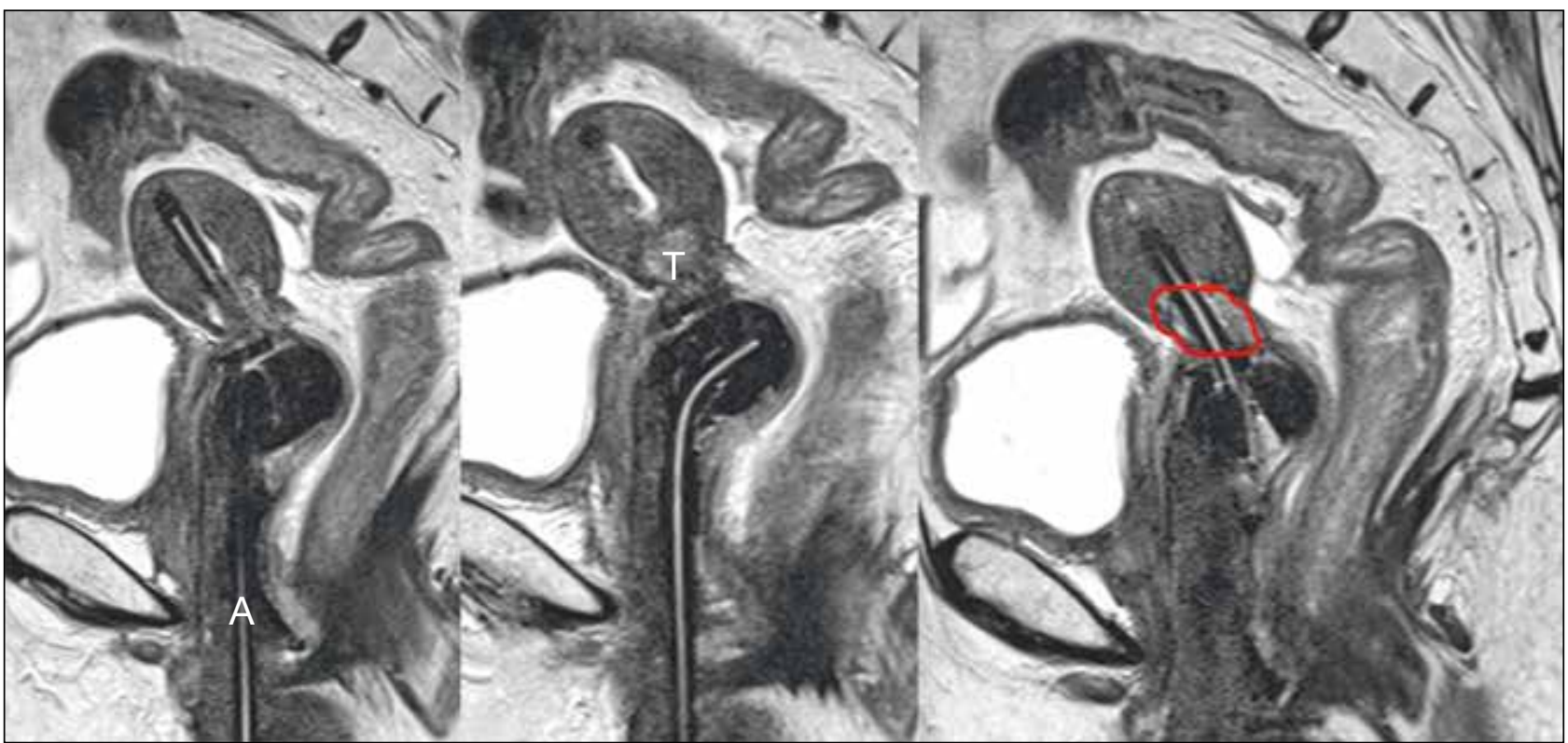

Figure 6. Magnetic resonance imaging-based image-guided brachytherapy. Applicators in situ (A) and residual tumour signal (T). Region of interest drawn around residual tumour signal for radiation planning.

adverse disease prognosis. ${ }^{34,35}$ The FIGO staging divides stage I disease into IA and IB, for superficial $(<50 \%$ thickness of myometrium) and deep ( $>50 \%$ thickness of myometrium) invasion, respectively. ${ }^{36}$

Lymphadenectomy in early endometrial cancer (stage I) is controversial and may bear no survival benefit. ${ }^{37,38}$ However, intermediate- and high-risk groups may benefit from pelvic and paraaortic lymphadenectomy. ${ }^{39}$ The presence of deep myometrial invasion or unfavourable histology (non-endometrioid adenocarcinoma) results in an upgrade from low risk to intermediate/high risk. Cervical stromal invasion is associated with increased likelihood of pelvic lymphadenopathy ${ }^{40,41}$ and an adverse prognosis. ${ }^{42,43}$

\section{Scanning Protocol and Standard of Measurement}

Most modern protocols incorporate T2, DWI, and postgadolinium images, either by multiphase or dynamic contrast-enhanced (DCE) MRI. Intravenous contrast aids tumour visualisation through increased contrast of the tumour with normal myometrium. The endometrial tumour shows less enhancement than normal myometrium. Depiction of myometrial invasion is at equilibrium phase ( $2 \mathrm{~min} 30 \mathrm{~s}$ after contrast injection). The cervical stroma enhances later than myometrium. Thus, invasion of cervical stroma is best assessed in delayed phase (3-5 min after contrast injection). ${ }^{15,44}$
DWI has also been used to depict deep myometrial invasion. Evidence suggested that DWI was at least equivalent to DCE, in detecting deep myometrial invasion (Figure 7). ${ }^{45,46}$ DWI has the potential to be an alternative to DCE in assessment of myometrial invasion, especially when intravenous contrast injection is contraindicated.

Methods of measuring depth of myometrial invasion vary, both in radiology and histology. This is further confounded when endometrial contour is distorted, as commonly occurs in the presence of benign pathology such as fibroids and adenomyosis causing irregular endometrial-myometrial junction, and in the presence of exophytic tumour. ${ }^{47,48}$ Measurement by subtraction might be a more reliable method. ${ }^{49}$ The thickness of adjacent uninvolved myometrium is first obtained. Then the distance between the serosa and outermost tumourfree myometrium is obtained. The depth of invasion is obtained by subtraction of the two numbers (Figure 8). This method attenuates the effect of endometrial distortion from irregular endometrial-myometrial junction and excludes exophytic areas from calculation.

\section{Nodal Staging}

Surgical staging remains the gold standard in determining nodal status in endometrial cancer. ${ }^{50,51}$ MRI with DWI showed higher sensitivity but lower specificity than FDG-PET/CT ( $83 \%$ vs. $39 \%$ and $51 \%$ vs. $96 \%$, respectively). ${ }^{52}$ In a meta-analysis of seven studies, the 


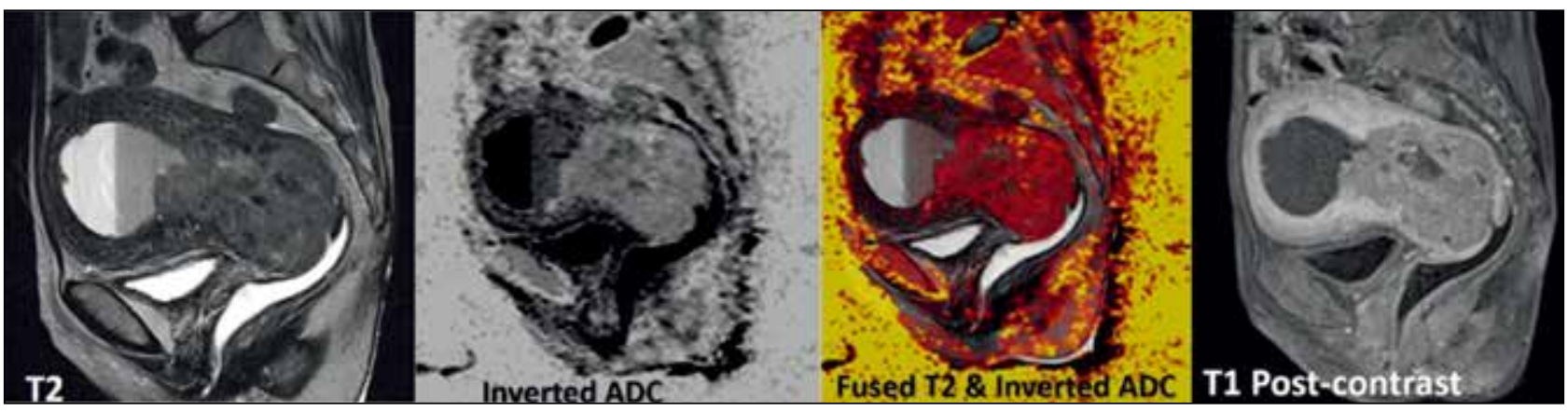

Figure 7. T2-weighted sagittal image showing a tumour at the lower segment of the uterus with cervical stromal invasion. Obstructive hydrometra with fluid-fluid level. Apparent diffusion coefficient (ADC) signal inverted fields on T2-weighted and post-contrast images of the same plane for comparison.

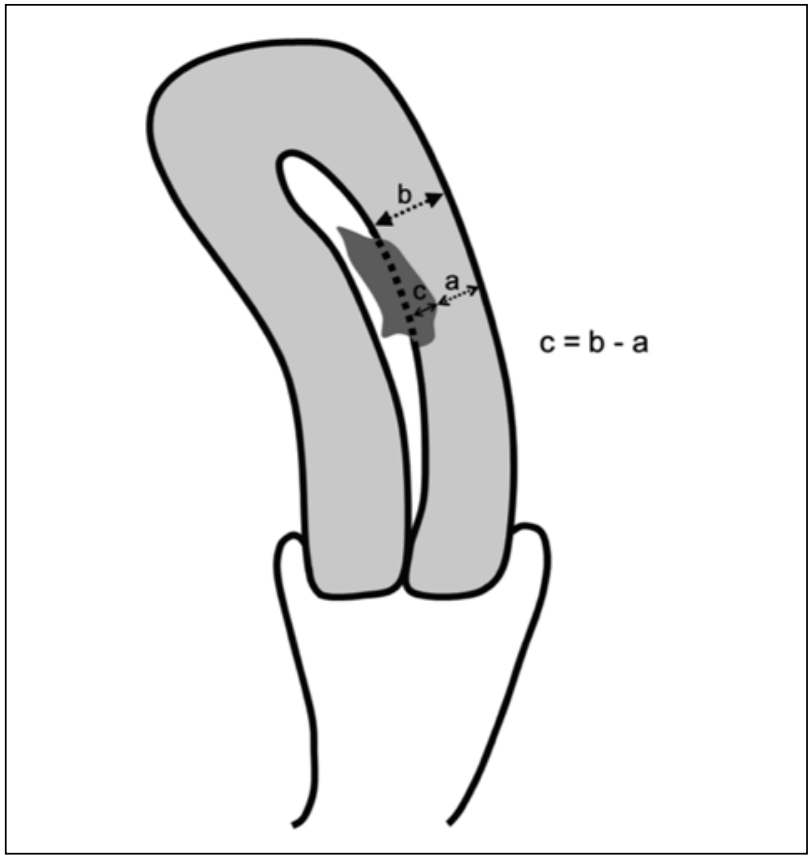

Figure 8. Schematic diagram illustrating the method of myometrial invasion depth. $\mathrm{a}=$ distance between serosa and outermost tumour-free myometrium, $b=$ thickness of adjacent normal myometrium, the depth of myometrial invasion, $\mathrm{c}$ is obtained by subtraction of two numbers.

sensitivity and specificity of FDG-PET/CT in detecting pelvic and/or paraaortic nodal metastasis were $63 \%$ and $95 \%$, respectively, with overall accuracy of $90 \% .^{53}$ The authors concluded that FDG-PET/CT was highly specific but only moderately sensitive, and thus cannot replace lymphadenectomy. Surgical staging remains important and the decision to perform lymphadenectomy or nodal sampling should be determined by pathological risk factors.

\section{OVARIAN CANCER Adnexal Mass Characterisation}

Endovaginal ultrasonography (USG) is usually the first line of investigation for pelvic masses. Terminology and measurements on endovaginal USG have been standardised by the International Ovarian Tumor Analysis group. ${ }^{54}$ The ROMA (Risk of Ovarian Malignancy Algorithm) score that incorporates ultrasound findings, CA125 and HE4 levels, is useful for prediction of the likelihood of malignancy of an adnexal mass. ${ }^{55}$

Adnexal lesions with benign USG features, for example, simple anechoic cysts $<5 \mathrm{~cm}$ in premenopausal women, can be safely dismissed. Depending on the USG features, some cases are safe to be followed up. ${ }^{56}$ However, with frankly malignant adnexal mass or a patient with a high ROMA score, CT can be performed for disease staging and assessment of extrapelvic spread. The vast diversity of ovarian masses, and the wide overlap of benign and malignant imaging features, make specific radiological diagnosis difficult. Methods to risk stratify adnexal lesions with quantitative and qualitative measures have been put forward ${ }^{57,58}$ MRI is useful in indeterminate adnexal masses for further characterisation. ${ }^{59}$ T1WI (with and without fat saturation) is useful to detect fatty components, mucin, and haemorrhage. Post-contrast T1WI is important in further lesion characterisation. T2WI detects cystic components and detailed anatomical characteristics. Morphological features favouring malignancy include diameter $>4 \mathrm{~cm}$, a complex cystic mass with thick internal septations, thickness of the wall $>3 \mathrm{~mm}$, lobulated contour, tiny amorphic calcifications, necrosis, papillary projections, and tumour vascularity (Figure 9). ${ }^{60,61}$ 
The apparent diffusion coefficient (ADC) value of the solid portion of an adnexal mass is lower in malignant than in benign lesions. With an ADC cut-off threshold value, malignant lesions can be excluded with high confidence. The ADC value could be a tool to streamline management strategies; however, inter-vendor and intersystem variability of $\mathrm{ADC}$ measurements render cross-centre validation difficult and thus limit the applicability of the method. ${ }^{62}$

In a retrospective analysis of 37 pre-operative DCEMRI performed for ovarian epithelial tumour, a Type 3 curve, defined by an initial rise in signal in the solid portion of an ovarian mass steeper than the myometrium, was present in malignant lesions and not in benign or borderline lesions. ${ }^{60}$ Other semi-quantitative DCE parameters offer useful information in that the absolute and relative maximum contrast enhancement could identify malignant lesions with $100 \%$ sensitivity and specificity, the but studied cohort was small $(n=26){ }^{63}$ A subsequent large-scale study with 102 patients also suggested the usefulness of DCE-MRI in differentiating benign from borderline and malignant tumours. ${ }^{64}$ Contrast enhancement can thus be considered a tool to identify lesions that are safe to follow-up.

The role of FDG-PET/CT in ovarian lesion characterisation is not clearly established. It has been suggested that FDG-PET/CT could assist in differentiating malignant from benign ovarian masses when DCE-MRI is indeterminate. ${ }^{65}$

\section{Peritoneal Disease}

Ovarian malignancies often present late with disseminated peritoneal disease. Cytoreductive surgery followed by systemic chemotherapy is the treatment of choice for advanced disease. The ability to achieve complete cytoreduction is related to improved survival rate. ${ }^{66-68}$

The volume of residual disease after cytoreductive surgery is one of the most important prognostic indicators. ${ }^{66,69}$ Optimal cytoreduction is defined as the largest residual disease of $<1 \mathrm{~cm} .{ }^{70}$ In recent years, there has been a shift in the surgical paradigm in pursuit of a cytoreductive goal of no gross residual disease, which has been shown to be associated with improved progression-free and overall survival. $^{71}$ Extensive surgical procedures are often required to achieve complete cytoreduction or minimal residual disease, and these can be technically challenging in patients with disseminated tumours. Neoadjuvant
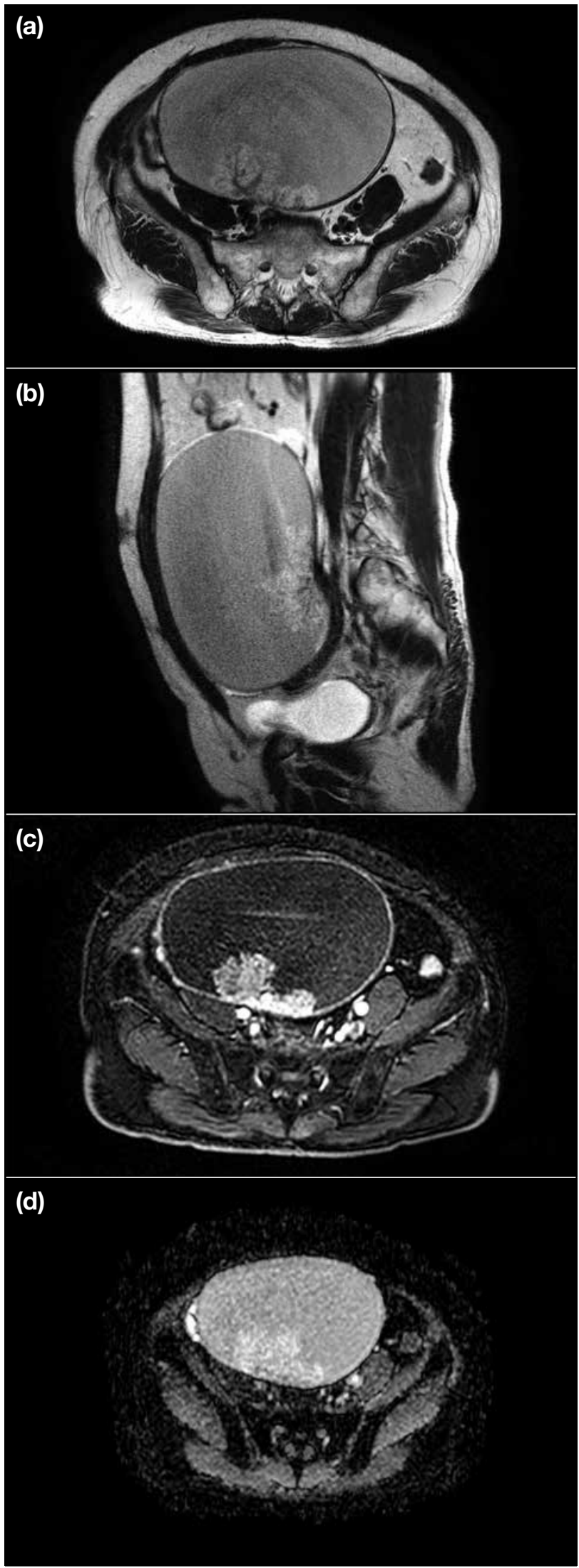

Figure 9. Serous borderline tumour. ( $a$ and $b$ ) T2-weighted axial and sagittal images showing a cystic lesion with enhancing solid component (c) but no restricted diffusion (d). 
chemotherapy followed by debulking surgery is an alternative to primary cytoreductive surgery, yielding similar outcomes. ${ }^{72}$ Resectability criteria differ across centres. In general, disease in the upper abdomen might require more complex surgical procedures, including splenectomy and diaphragmatic resection, and likely involvement of more than one surgical specialty. The European Society of Urogenital Radiology guidelines suggest several negative prognostic factors for complete cytoreduction, including deposits $>2 \mathrm{~cm}$ in the upper abdomen, parenchymal or subcapsular involvement of the liver and spleen, involvement of small bowel mesentery, and lymph node involvement above the renal hila. $^{73}$

Contrast-enhanced CT of the abdomen and pelvis is currently the first-line radiological investigation for detection of peritoneal disease. Its reported sensitivity in detecting peritoneal metastasis in ovarian cancer ranges
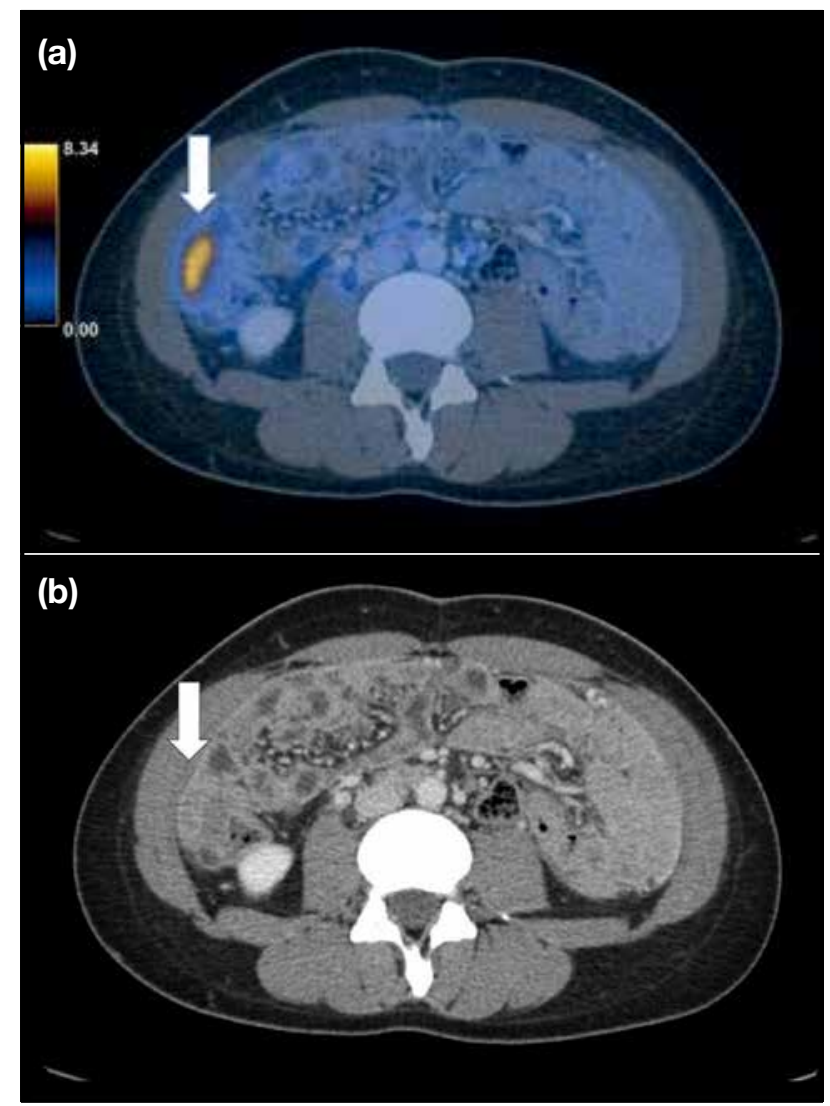

Figure 10. (a) 18-fluorodeoxyglucose positron emission tomography/computed tomography. Uptake in peritoneal deposits in the right paracolic gutter (arrows) which is subtle on contrastenhanced computed tomography (b). from $85 \%$ to $93 \%$, but this substantially drops to $25 \%$ to $50 \%$ for subcentimetre peritoneal implants. ${ }^{74}$

Techniques such as FDG-PET/CT and DWI enhance the visibility of peritoneal metastases (Figures 10 and 11)..$^{75,76}$
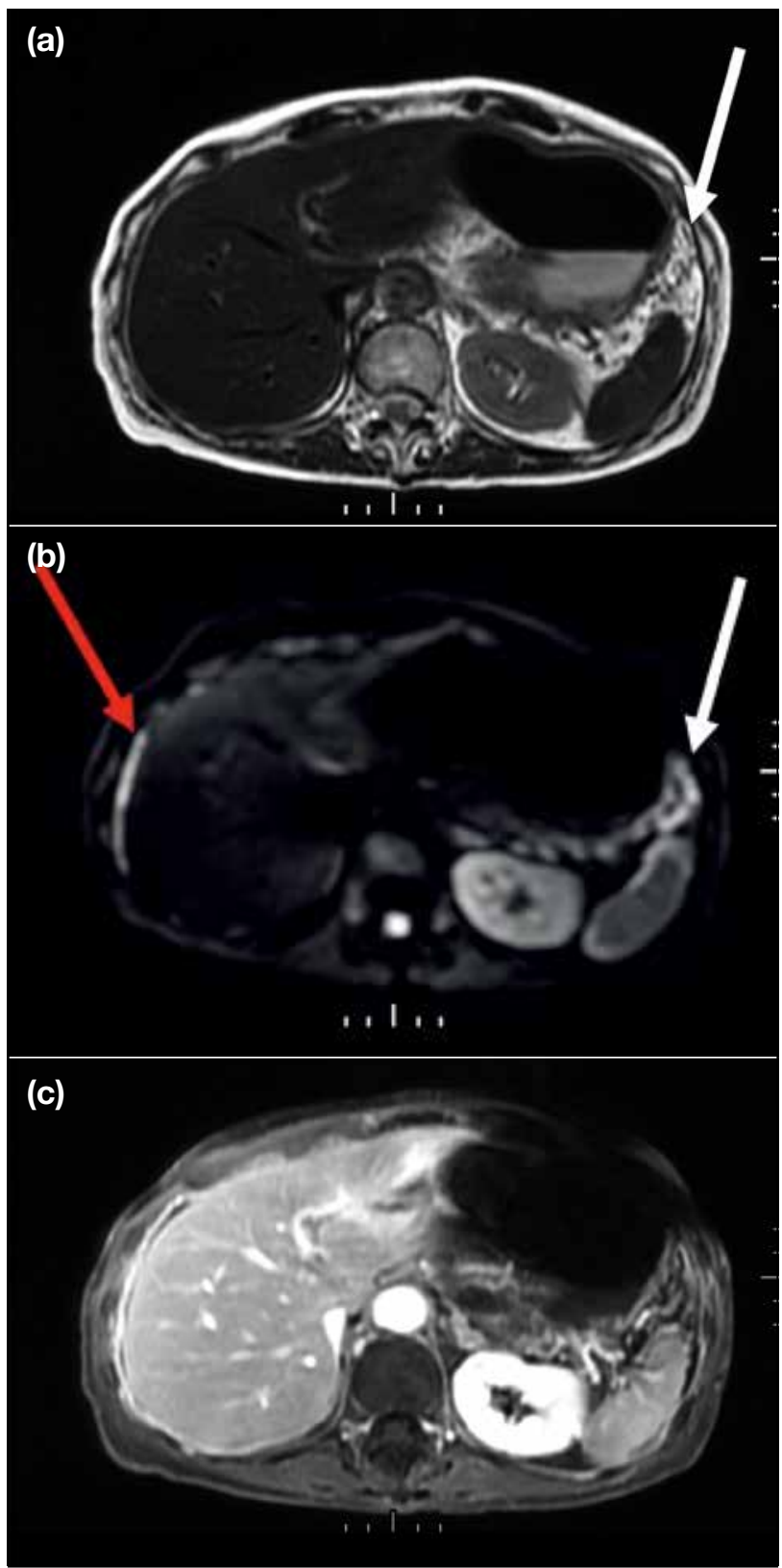

Figure 11. Ovarian cancer with peritoneal carcinomatosis. (a) T2-weighted axial image showing fat stranding along the lienogastric ligament (white arrow). (b) Diffusion-weighted imaging $(b=800)$ demonstrates hyperintense signal over left upper abdomen corresponding to the stranding along the lienogastric ligament (white arrow) and additional perihepatic disease, which is not visible on T2-weighted axial image (red arrow). (c) Corresponding post-contrast image confirming these findings. 
Table 2. Summary of literature comparing the diagnostic power of conventional CT, FDG-PET/CT and MRI in detection of peritoneal disease in ovarian cancer.

\begin{tabular}{|c|c|c|c|c|c|c|c|c|}
\hline Study & $\begin{array}{l}\text { Cohort } \\
\text { size }\end{array}$ & $\begin{array}{l}\text { Modalities } \\
\text { compared }\end{array}$ & Endpoint & Accuracy fi & igures & & & Conclusions \\
\hline Schmidt et al ${ }^{79}$ & 15 & $\begin{array}{l}\text { CT, MRI, } \\
\text { FDG-PET/CT }\end{array}$ & Peritoneal carcinomatosis & $\begin{array}{l}\text { Sensitivity } \\
\text { Specificity } \\
\text { PPV } \\
\text { NPV } \\
\text { Accuracy }\end{array}$ & $\begin{array}{c}\text { MRI } \\
98 \\
84 \\
91 \\
96 \\
93\end{array}$ & $\begin{array}{l}\text { FDG-PET/CT } \\
95 \\
96 \\
98 \\
92 \\
96\end{array}$ & $\begin{array}{l}\text { CT } \\
96 \\
92 \\
95 \\
94 \\
95\end{array}$ & $\begin{array}{l}\mathrm{CT}, \mathrm{MRI} \text { and FDG-PET/CT } \\
\text { are of similar diagnostic } \\
\text { accuracies }\end{array}$ \\
\hline Low et $\mathrm{al}^{80}$ & 22 & CT and MRI & $\begin{array}{l}\text { CT and MRI predicted } \\
\text { peritoneal carcinomatosis } \\
\text { index (PCI) }\end{array}$ & Accuracy & & $\begin{array}{c}\text { MRI } \\
91\end{array}$ & $\begin{array}{l}\text { CT } \\
50\end{array}$ & $\begin{array}{l}\text { MRI is more accurate than } \\
\mathrm{CT} \text { to predict PCl score }\end{array}$ \\
\hline $\begin{array}{l}\text { Lopez-Lopez } \\
\text { et al }{ }^{81}\end{array}$ & 59 & $\begin{array}{l}\text { CT and } \\
\text { FDG-PET/CT }\end{array}$ & $\mathrm{PCl}$ & $\begin{array}{l}\text { Sensitivity } \\
\text { Specificity } \\
\text { PPV } \\
\text { NPV }\end{array}$ & & $\begin{array}{c}\text { FDG-PET/CT } \\
24 \\
93 \\
66 \\
68\end{array}$ & $\begin{array}{l}\text { CT } \\
35 \\
98 \\
90 \\
72\end{array}$ & $\begin{array}{l}\text { CT shows better } \\
\text { diagnostic result as } \\
\text { compared to FDG-PET/CT } \\
\text { in detection of peritoneal } \\
\text { disease }\end{array}$ \\
\hline Kim et $\mathrm{al}{ }^{82}$ & 46 & $\begin{array}{l}\text { CT and } \\
\text { FDG-PET/CT }\end{array}$ & $\begin{array}{l}\text { Presence of peritoneal } \\
\text { carcinomatosis }\end{array}$ & $\begin{array}{l}\text { Sensitivity } \\
\text { Specificity } \\
\text { PPV } \\
\text { NPV } \\
\text { Accuracy }\end{array}$ & & $\begin{array}{c}\text { FDG-PET/CT } \\
96 \\
90 \\
93 \\
95 \\
94\end{array}$ & $\begin{array}{l}\text { CT } \\
89 \\
65 \\
77 \\
81 \\
78\end{array}$ & $\begin{array}{l}\text { FDG-PET/CT is more } \\
\text { accurate than CT }\end{array}$ \\
\hline Rubini et $\mathrm{a}^{83}$ & 51 & $\begin{array}{l}\text { CT and } \\
\text { FDG-PET/CT }\end{array}$ & $\begin{array}{l}\text { Presence of peritoneal } \\
\text { carcinomatosis }\end{array}$ & $\begin{array}{l}\text { Sensitivity } \\
\text { Specificity } \\
\text { PPV } \\
\text { NPV } \\
\text { Accuracy }\end{array}$ & & $\begin{array}{c}\text { FDG-PET/CT } \\
79 \\
91 \\
92 \\
78 \\
84\end{array}$ & $\begin{array}{l}\text { CT } \\
54 \\
61 \\
62 \\
51 \\
57\end{array}$ & $\begin{array}{l}\text { FDG-PET/CT is more } \\
\text { accurate than CT in } \\
\text { detection of peritoneal } \\
\text { metastasis }\end{array}$ \\
\hline Low et $\mathrm{al}^{76}$ & 34 & $\mathrm{MRI}$ and $\mathrm{DWI}$ & Detection by site & $\begin{array}{l}\text { Sensitivity } \\
\text { Specificity } \\
\text { Accuracy }\end{array}$ & $\begin{array}{r}\text { DWI } \\
100 \\
75 \\
86 \\
\end{array}$ & $\begin{array}{l}\text { Conventional C } \\
\text { MRI } \\
97 \\
57 \\
88 \\
\end{array}$ & $\begin{array}{l}\text { Combined } \\
\qquad \begin{array}{r}100 \\
71 \\
94 \\
\end{array}\end{array}$ & $\begin{array}{l}\text { Adding DWI to routine MRI } \\
\text { improves accuracy }\end{array}$ \\
\hline
\end{tabular}

Abbreviations: $\mathrm{CT}$ = computed tomography; DWI = diffusion-weighted imaging; FDG-PET/CT = 18-fluorodeoxyglucose positron emission tomography/computed tomography; MRI = magnetic resonance imaging; NPV = negative predictive values; $\mathrm{PCl}=$ peritoneal cancer index; PPV = positive predictive values.

DWI can detect peritoneal deposits with the additional advantage of no intravenous contrast administration. It has reported sensitivity and specificity of up to $95 \%$ and $95 \%$, respectively. ${ }^{77}$ False positives from bowel content can be reduced by using high b-value images such as $800 \mathrm{~s} / \mathrm{mm}^{2}$. The high signal of peritoneal deposits on high b-value DWI-MRI adds to lesion conspicuity.

FDG-PET/CT has been suggested to be more sensitive and specific in predicting disease resectability as compared with conventional contrast-enhanced CT alone..$^{78}$ Table $2^{76,79-83}$ summarises current evidence of the use of FDG-PET/CT and MRI in detection of peritoneal disease in ovarian cancer.

\section{CONCLUSION}

Imaging plays a crucial role in gynaecological oncology, from diagnosis to treatment stratification. The revised 2018 FIGO incorporates radiological findings in cervical cancer staging. Use of MRI planning in image-guided brachytherapy for cervical cancer improves treatment outcome. MRI is highly accurate in depicting myometrial invasion and cervical stromal invasion in endometrial cancer. Functional imaging is effective for detecting peritoneal carcinomatosis.

\section{REFERENCES}

1. Hong Kong Cancer Registry. Cervical cancer in 2015. Available from: http://www3 .ha.org.hk/cancereg/pdf/factsheet/2015/ cx_2015.pdf. Accessed 1 Nov 2018.

2. Machida H, Iwata T, Okugawa K, Matsuo K, Saito T, Tanaka K, et al. Fertility-sparing trachelectomy for early-stage cervical cancer: A proposal of an ideal candidate. Gynecol Oncol. 2020;156:341-8.

3. Bogani G, Chiappa V, Vinti D, Somigliana E, Filippi F, Murru G, et al. Long-term results of fertility-sparing treatment for early-stage cervical cancer. Gynecol Oncol. 2019;154:89-94. 
4. Morris M, Eifel PJ, Lu J, Grigsby PW, Levenback C, Stevens RE, et al. Pelvic radiation with concurrent chemotherapy compared with pelvic and para-aortic radiation for high-risk cervical cancer. N Engl J Med. 1999;340:1137-43.

5. Rose PG, Bundy BN, Watkins EB, Thigpen JT, Deppe G, Maiman MA, et al. Concurrent cisplatin-based radiotherapy and chemotherapy for locally advanced cervical cancer. N Engl J Med. 1999;340:1144-53.

6. Bhatla N, Aoki D, Sharma DN, Sankaranarayanan R. Cancer of the cervix uteri. Int J Gynaecol Obstet. 2018;143 Suppl 2:22-36.

7. Woo S, Suh CH, Kim SY, Cho JY, Kim SH. Magnetic resonance imaging for detection of parametrial invasion in cervical cancer: An updated systematic review and meta-analysis of the literature between 2012 and 2016. Eur Radiol. 2018;28:530-41.

8. Balleyguier C,SalaE,DaCunhaT, Bergman A,Brkljacic B,Danza F, et al. Staging of uterine cervical cancer with MRI: guidelines of the European Society of Urogenital Radiology. Eur Radiol. 2011;21:1102-10.

9. Miccò M, Sala E, Lakhman Y, Hricak H, Vargas HA. Role of imaging in the pretreatment evaluation of common gynecological cancers. Womens Health (Lond). 2014;10:299-321.

10. Sala E, Micco M, Burger IA, Yaker D, Kollmeier MA, Goldman DA, et al. Complementary prognostic value of pelvic magnetic resonance imaging and whole-body fluorodeoxyglucose positron emission tomography/computed tomography in the pretreatment assessment of patients with cervical cancer. Int J Gynecol Cancer. 2015;25:1461-7.

11. Nam H, Huh SJ, Park W, Bae DS, Kim BG, Lee JH, et al. Prognostic significance of MRI-detected bladder muscle and/or serosal invasion in patients with cervical cancer treated with radiotherapy. Br J Radiol. 2010;83:868-73.

12. Patel S, Liyanage SH, Sahdev A, Rockall AG, Reznek RH. Imaging of endometrial and cervical cancer. Insights Imaging. 2010;1:30928.

13. Engelaere C, Poncelet E, Durot C, Dohan A, Rousset P, Hoeffel C. Pelvic MRI: Is endovaginal or rectal filling needed? Korean J Radiol. 2018;19:397-409.

14. Brown MA, Mattrey RF, Stamato S, Sirlin CB. MRI of the female pelvis using vaginal gel. AJR Am J Roentgenol. 2005;185:1221-7.

15. Sala E, Wakely S, Senior E, Lomas D. MRI of malignant neoplasms of the uterine corpus and cervix. AJR Am J Roentgenol. 2007; 188:1577-87.

16. Kwon J, Eom KY, Kim YS, Park W, Chun M, Lee J, et al. The prognostic impact of the number of metastatic lymph nodes and a new prognostic scoring system for recurrence in early-stage cervical cancer with high risk factors: a multicenter cohort study (KROG 15-04). Cancer Res Treat. 2018;50:964-74.

17. Choi HJ, Kim SH, Seo SS, Kang S, Lee S, Kim JY, et al. MRI for pretreatment lymph node staging in uterine cervical cancer. AJR Am J Roentgenol. 2006;187:W538-43.

18. Shen G, Zhou H, Jia Z, Deng H. Diagnostic performance of diffusion-weighted MRI for detection of pelvic metastatic lymph nodes in patients with cervical cancer: a systematic review and meta-analysis. Br J Radiol. 2015;88:20150063.

19. Choi HJ, Ju W, Myung SK, Kim Y. Diagnostic performance of computer tomography, magnetic resonance imaging, and positron emission tomography or positron emission tomography/computer tomography for detection of metastatic lymph nodes in patients with cervical cancer: meta-analysis. Cancer Sci. 2010;101:1471-9.

20. Liu B, Gao S, Li S. A comprehensive comparison of CT, MRI, positron emission tomography or positron emission tomography/ $\mathrm{CT}$, and diffusion weighted imaging-MRI for detecting the lymph nodes metastases in patients with cervical cancer: a meta-analysis based on 67 studies. Gynecol Obstet Invest. 2017;82:209-22.

21. Stein EB, Hansen JM, Maturen KE. Fertility-sparing approaches in gynecologic oncology: role of imaging in treatment planning. Radiol Clin North Am. 2020;58:401-12.

22. Alvarez RM, Biliatis I, Rockall A, Papadakou E, Sohaib SA, deSouza NM, et al. MRI measurement of residual cervical length after radical trachelectomy for cervical cancer and the risk of adverse pregnancy outcomes: a blinded imaging analysis. BJOG. 2018;125:1726-33.

23. Lakhman Y, Akin O, Park KJ, Sarasohn DM, Zheng J, Goldman DA, et al. Stage IB1 cervical cancer: role of preoperative MR imaging in selection of patients for fertility-sparing radical trachelectomy. Radiology. 2013;269:149-58.

24. Noël P, Dubé M,Plante M,St-Laurent G. Early cervical carcinoma and fertility-sparing treatment options: MR imaging as a tool in patient selection and a follow-up modality. Radiographics. 2014;34:1099-119.

25. Rockall AG, Qureshi M, Papadopoulou I, Saso S, Butterfield N, Thomassin-Naggara I, et al. Role of imaging in fertilitysparing treatment of gynecologic malignancies. Radiographics. 2016;36:2214-33.

26. Mahantshetty U, Swamidas J, Khanna N, Engineer R, Merchant N, Shrivastava S. Magnetic resonance image-based dose volume parameters and clinical outcome with high dose rate brachytherapy in cervical cancers - a validation of GYN GEC-ESTRO brachytherapy recommendations. Clin Oncol (R Coll Radiol). 2011;23:376-7.

27. Derks K, Steenhuijsen JL, van den Berg HA, Houterman S, Cnossen J, van Haaren P, et al. Impact of brachytherapy technique (2D versus $3 \mathrm{D}$ ) on outcome following radiotherapy of cervical cancer. J Contemp Brachytherapy. 2018;10:17-25.

28. Potter R, Kirisits C, Fidarova EF, Dimopoulos JC, Berger D, Tanderup K, et al. Present status and future of high-precision image guided adaptive brachytherapy for cervix carcinoma. Acta Oncol. 2008;47:1325-36.

29. Dimopoulos JC, Petrow P, Tanderup K, Petric P, Berger D, Kirisits C, et al. Recommendations from Gynaecological (GYN) GEC-ESTRO Working Group (IV): Basic principles and parameters for MR imaging within the frame of image based adaptive cervix cancer brachytherapy. Radiother Oncol. 2012;103:113-22.

30. Cibula D, Pötter R, Planchamp F, Avall-Lundqvist E, Fischerova D, Haie-Meder C, et al. The European Society of Gynaecological Oncology/European Society for Radiotherapy and Oncology/ European Society of Pathology guidelines for the management of patients with cervical cancer. Virchows Arch. 2018;472:919-36.

31. Kim H, Houser CJ, Kalash R, Maceil CA, Palestra B, Malush D, et al. Workflow and efficiency in MRI-based high-dose-rate brachytherapy for cervical cancer in a high-volume brachytherapy center. Brachytherapy. 2018;17:753-60.

32. Petric P, Dimopoulos J, Kirisits C, Berger D, Hudej R, Pötter R. Inter- and intraobserver variation in HR-CTV contouring: intercomparison of transverse and paratransverse image orientation in 3D-MRI assisted cervix cancer brachytherapy. Radiother Oncol. 2008;89:164-71.

33. Lortet-Tieulent J, Ferlay J, Bray F, Jemal A. International patterns and trends in endometrial cancer incidence, 1978-2013. J Natl Cancer Inst. 2018;110:354-61.

34. Creasman WT, Morrow CP, Bundy BN, Homesley HD, Graham JE, Heller PB. Surgical pathologic spread patterns of endometrial cancer. A Gynecologic Oncology Group study. Cancer. 1987;60(8 Suppl):2035-41.

35. Larson DM, Connor GP, Broste SK, Krawisz BR, Johnson KK. Prognostic significance of gross myometrial invasion with 
endometrial cancer. Obstet Gynecol. 1996;88:394-8.

36. Amant F, Mirza MR, Koskas M, Creutzberg CL. Cancer of the corpus uteri. Int J Gynecol Obstet. 2018;143 Suppl 2:37-50.

37. Benedette Panici P, Basile S, Maneschi F, Alberto Lissoni A, Signorelli M, Scambia G, et al. Systemic pelvic lymphadenectomy versus no lymphadenectomy in early stage endometrial cancer: a randomized clinical trial. J Nat Cancer Inst. 2008;100:1707-16.

38. ASTEC study group; Kitchener H, Swart AM, Qian Q, Amos C, Parmar MK. Efficacy of systematic pelvic lymphadenectomy in endometrial cancer (MRC ASTEC trial): a randomised study. Lancet. 2009;373:125-36.

39. Todo Y, Kato H, Kaneuchi M, Watari H, Takeda M, Sakuragi N. Survival effect of para-aortic lymphadenectomy in endometrial cancer (SEPAL study): a retrospective cohort analysis. Lancet. 2010;375:1165-72.

40. Lin G, Huang YT, Chao A, Lin YC, Yang LY, Wu RC, et al. Endometrial cancer with cervical stromal invasion: diagnostic accuracy of diffusion-weighted and dynamic contrast enhanced MR imaging at 3T. Eur Radiol. 2017;27:1867-76.

41. Solmaz U, Mat E, Dereli M, Turan V, Gungorduk K, Hasdemir P, et al.Lymphovascular space invasion and cervical stromal invasion are independent risk factors for nodal metastasis in endometrioid endometrial cancer. Aust N Z J Obstet Gynaecol. 2015;55:81-6.

42. Taşkın S, Ortaç F, Kahraman K, Göç G, Öztuna D, Güngör M. Cervical stromal involvement can predict survival in advanced endometrial carcinoma: a review of 67 patients. Int J Clin Oncol. 2013;18:105-9.

43. Kwon JS, Qiu F, Saskin R, Carey MS. Are uterine risk factors more important than nodal status in predicting survival in endometrial cancer? Obstet Gynecol. 2009;114:736-43

44. Nougaret S, Horta M, Sala E, Lakhman Y, Thomassin-Naggara I, Kido A, et al. Endometrial cancer MRI staging: updated guidelines of the European Society of Urogenital Radiology. Eur Radiol. 2019;29:792-805.

45. Beddy P, Moyle P, Kataoka M, Yamamoto AK, Joubert I, Lomas D, et al. Evaluation of depth of myometrial invasion and overall staging in endometrial cancer: comparison of diffusion-weighted and dynamic contrast-enhanced MR imaging. Radiology. 2012;262:530-7.

46. Thieme SF, Collettini F, Sehouli J, Biocca L, Lella A, Wagner M, et al. Preoperative evaluation of myometrial invasion in endometrial carcinoma: prospective intra-individual comparison of magnetic resonance volumetry, diffusion-weighted and dynamic contrast-enhanced magnetic resonance imaging. Anticancer Res. 2018;38:4813-7.

47. Ali A, Black D, Soslow RA. Difficulties in assessing the depth of myometrial invasion in endometrial carcinoma. Int J Gynecol Pathol. 2007;26:115-23.

48. College of American Pathologists. Protocol for the Examination of Specimens From Patients With Carcinoma and Carcinosarcoma of the Endometrium. 2017. Available from: https://documents.cap. org/protocols/cp-endometrium-2017-v4000.pdf. Accessed 1 Nov 2018.

49. van der Putten LJ, van de Vijver K, Bartosch C, Davidson B, Gatius S, Matias-Guiu X, et al. Reproducibility of measurement of myometrial invasion in endometrial carcinoma. Virchows Arch. 2017;470:63-8.

50. Rungruang $B$, Olawaiye $A B$. Comprehensive surgical staging for endometrial cancer. Rev Obstet Gynecol. 2012;5:28-34.

51. Abu-Rustum NR. Sentinel lymph node mapping for endometrial cancer: a modern approach to surgical staging. J Natl Compr Canc Netw. 2014;12:288-97.

52. Kitajima K, Yamasaki E, Kaji Y, Murakami K, Sugimura K.
Comparison of DWI and PET/CT in evaluation of lymph node metastasis in uterine cancer. World J Radiol. 2012;4:207-14.

53. Chang MC, Chen JH, Liang JA, Yang KT, Cheng KY, Kao CH. 18F-FDG PET or PET/CT for detection of metastatic lymph nodes in patients with endometrial cancer: a systematic review and metaanalysis. Eur J Radiol. 2012;81:3511-7.

54. Timmerman D, Valentin L, Bourne TH, Collins WP, Verrelst H, Vergote I, et al. Terms, definitions and measurements to describe the sonographic features of adnexal tumors: a consensus opinion from the International Ovarian Tumor Analysis (IOTA) Group. Ultrasound Obstet Gynecol. 2000;16:500-5.

55. Anton C, Carvalho FM, Oliveira EI, Maciel GA, Baracat EC, Carvalho JP. A comparison of CA125, HE4, risk ovarian malignancy algorithm (ROMA), and risk malignancy index (RMI) for the classification of ovarian masses. Clinics (Sao Paulo). 2012;67:437-41.

56. Levine D, Brown DL, Andreotti RF, Benacerraf B, Benson CB, Brewster WR, et al. Management of asymptomatic ovarian and other adnexal cysts imaged at US: Society of Radiologists in Ultrasound Consensus Conference Statement. Radiology. 2010;256:943-54.

57. Thomassin-Naggara I, Poncelet E, Jalaguier-Coudray A, Guerra A, Fournier LS, Stojanovic S, et al. Ovarian-Adnexal Reporting Data System Magnetic Resonance Imaging (O-RADS MRI) score for risk stratification of sonographically indeterminate adnexal masses. JAMA Netw Open. 2020;3:e1919896.

58. Rockall A,Forstner R. Adnexal diseases.In: Hodler J,Kubik-HuchRA, von Schulthess GK, editors. Diseases of the Abdomen and Pelvis 2018-2021: Diagnostic Imaging-IDKD Book. Cham (CH): Springer; 2018. p 75-84.

59. Kinkel K, Lu Y, Mehdizade A, Pelte MF, Hricak H. Indeterminate ovarian mass at US: incremental value of second imaging test for characterization - meta-analysis and Bayesian analysis. Radiology. 2005;236:85-94.

60. Thomassin-Naggara I, Daraï E, Cuenod CA, Rouzier R, Callard P, Bazot M. Dynamic contrast-enhanced magnetic resonance imaging: A useful tool for characterizing ovarian epithelial tumors. J Magn Reson Imaging. 2008;28:111-20.

61. Valentini AL, Gui B, Miccò M, Mingote MC, De Gaetano AM, Ninivaggi $\mathrm{V}$, et al. Benign and suspicious ovarian masses-MR imaging criteria for characterization: Pictorial review. J Oncol. 2012;2012:481806.

62. Davarpanah AH, Kambadakone A, Holalkere NS, Guimaraes AR, Hahn PF, Lee SI. Diffusion MRI of uterine and ovarian masses: identifying the benign lesions. Abdom Radiol (NY). 2016;41:246675.

63. Dilks P, Narayanan P, Reznek R, Sahdev A, Rockall A. Can quantitative dynamic contrast-enhanced MRI independently characterize an ovarian mass? Eur Radiol. 2010;20:2176-83.

64. Li HM, Qiang JW, Ma FH, Zhao SH. The value of dynamic contrast-enhanced MRI in characterizing complex ovarian tumors. J Ovarian Res. 2017;10:4.

65. Tsuboyama T, Tatsumi M, Onishi H, Nakamoto A, Kim T, Hori M, et al. Assessment of combination of contrast-enhanced magnetic resonance imaging and positron emission tomography/computed tomography for evaluation of ovarian masses. Invest Radiol. 2014;49:524-31.

66. Bristow RE, Tomacruz RS, Armstrong DK, Trimble EL, Montz FJ Survival effect of maximal cytoreductive surgery for advanced ovarian carcinoma during the platinum era: a meta-analysis. J Clin Oncol. 2002;20:1248-59.

67. Chang SJ, Hodeib M, Chang J, Bristow RE. Survival impact of complete cytoreduction to no gross residual disease for 
advanced-stage ovarian cancer: a meta-analysis. Gynecol Oncol. 2013;130:493-8.

68. Balci S, Basturk O, Saka B, Bagci P, Postlewait LM, Tajiri T, et al. Substaging nodal status in ampullary carcinomas has significant prognostic value: proposed revised staging based on an analysis of 313 well-characterized cases. Ann Surg Oncol. 2015;22:4392-401.

69. Hacker NF, Berek JS, Lagasse LD, Nieberg RK, Elashoff RM. Primary cytoreductive surgery for epithelial ovarian cancer. Obstet Gynecol. 1983;61:413-20.

70. Whitney C, Spirtos N. Gynecologic Oncology Group Surgical Procedures Manual. 2009. Available from: https://www.semanticscholar.org/paper/GynecologicOncology-Group-Surgical-Procedures-Whitney-Spirtos/ ef77d3d5e22d5515d42c9380df42ba6e0d409d54. Accessed 2 Nov 2018.

71. Tseng JH, Cowan RA, Zhou Q, Iasonos A, Byrne M, Polcino T, et al. Continuous improvement in primary debulking surgery for advanced ovarian cancer: do increased complete gross resection rates independently lead to increased progression-free and overall survival? Gynecol Oncol. 2018;151:24-31.

72. Vergote I, Tropé CG, Amant F, Kristensen GB, Ehlen T, Johnson N, et al. Neoadjuvant chemotherapy or primary surgery in stage IIIC or IV ovarian cancer. N Engl J Med. 2010;363:943-53.

73. Forstner R, Sala E, Kinkel K, Spencer JA, European Society of Urogenital Radiology. ESUR guidelines: ovarian cancer staging and follow-up. Eur Radiol. 2010;20:2773-80.

74. Coakley FV, Choi PH, Gougoutas CA, Pothuri B, Venkatraman E, Chi D, et al. Peritoneal metastases: detection with spiral CT in patients with ovarian cancer. Radiology. 2002;223:495-9.

75. Iafrate $F$, Ciolina $M$, Sammartino $P$, Baldassari $P$, Rengo $M$, Lucchesi $\mathrm{P}$, et al. Peritoneal carcinomatosis: imaging with 64MDCT and 3T MRI with diffusion-weighted imaging. Abdom Imaging. 2012;37:616-27.
76. Low RN, Sebrechts CP, Barone RM, Muller W. Diffusion-weighted MRI of peritoneal tumors: comparison with conventional MRI and surgical and histopathologic findings - a feasibility study. AJR Am J Roentgenol. 2009;193:461-70.

77. Fujii S, Matsusue E, Kanasaki Y, Kanamori Y, Nakanishi J, Sugihara $S$, et al. Detection of peritoneal dissemination in gynecological malignancy: evaluation by diffusion-weighted MR imaging. Eur Radiol. 2008;18:18-23.

78. Roze JF, Hoogendam JP, van de Wetering FT, Spijker R, Verleye L, Vlayen J, et al.Positron emission tomography (PET) and magnetic resonance imaging (MRI) for assessing tumour resectability in advanced epithelial ovarian/fallopian tube/primary peritoneal cancer. Cochrane Database Syst Rev. 2018;10:CD012567.

79. Schmidt S, Meuli RA, Achtari C, Prior JO. Peritoneal carcinomatosis in primary ovarian cancer staging: comparison between MDCT, MRI, and 18F-FDG PET/CT. Clin Nucl Med. 2015;40:371-7.

80. Low RN, Barone RM, Lucero J. Comparison of MRI and CT for predicting the Peritoneal Cancer Index (PCI) preoperatively in patients being considered for cytoreductive surgical procedures. Ann Surg Oncol. 2015;22:1708-15.

81. Lopez-Lopez V, Cascales-Campos P, Gil J, Frutos L, Andrade RJ, Fuster-Quiñonero M, et al. Use of 18F-FDG PET/CT in the preoperative evaluation of patients diagnosed with peritoneal carcinomatosis of ovarian origin, candidates to cytoreduction and hipec. A pending issue. Eur J Radiol. 2016;85:1824-8.

82. Kim HW, Won KS, Zeon SK, Ahn BC, Gayed IW. Peritoneal carcinomatosis in patients with ovarian cancer: enhanced CT versus 18F-FDG PET/CT. Clin Nucl Med. 2013;38:93-7.

83. Rubini G, Altini C, Notaristefano A, Merenda N, Rubini D, Ianora AA, et al. Role of 18F-FDG PET/CT in diagnosing peritoneal carcinomatosis in the restaging of patient with ovarian cancer as compared to contrast enhanced CT and tumor marker Ca-125. Rev Esp Med Nucl Imagen Mol. 2014;33:22-7. 